\title{
Kombinasi Logika Fuzzy Dan Metode Simple Additive Weighted (SAW) Untuk Membantu Merekomendasikan Jurusan Pada Perguruan Tinggi
}

\author{
Deni Kurniawan \\ Faculty Computer Science, Informatics and Business Institute Darmajaya \\ Strret. 2.A. Pagar Alam No. 93, Bandar Lampung - Indonesia 35142
}

denikurniawan@gmail.com

\begin{abstract}
Intisari- Penjurusan pada sekolah menengah ke atas memiliki tujuan antara lain mengelompokkan siswa sesuai kecakapan, kemampuan, bakat, dan minat yang relatif sama. Selain itu penentuan jurusan membantu mempersiapkan siswa melanjutkan studi ke Perguruan Tinggi dan memilih dunia kerja. Berdasar penelitian Indonesia Career Center Network (ICCN) tahun 2017, diketahui sebanyak $87 \%$ mahasiswa Indonesia mengakui bahwa jurusan yang diambil tidak sesuai dengan minatnya. Selain itu sebanyak 71,7\% memiliki profesi yang tidak sesuai dengan pendidikannya. Penelitian yang dilakukan menunjukkan ketidaksesuaian jurusan siswa sebanyak 40\%. Berdasarkan ketidaksesuaian kompetensi siswa terhadap jurusan yang ditempuhnya maka siswa selaku pembuat keputusan harus benar - benar mempertimbangkan kriteria kemampuan dan keinginan. Kriteria yang ditetapkan dalam studi kasus ini adalah nilai UN Bahasa Indonesia, Bahasa Inggris, Matematika, Fisika, Kimia dan Biologi. Nilai Ujian Nasional (UN) siswa, selanjutnya akan dihitung menggunakan metode Fuzzy dan Simple Additive Weighting (SAW) untuk mendapatkan rekomendasi jurusan yang dapat diambil calon mahasiswa. Hasil dari penelitian yang telah dilakukan adalah berupa pembuatan pengetahuan dalam aplikasi pendukung keputusan untuk merekomendasikan jurusan kepada siswa yang akan melanjutkan ke jenjang perguruan tinggi. Kombinasi metode Fuzzy dan SAW dapat digunakan dalam merekomendasikan untuk penentuan jurusan. Diharapkan dengan adanya aplikasi ini dapat membantu para siswa dalam mengambil jurusan yang tepat sesuai minat dan bidangnya.

Kata kunci-Fuzzy, SAW, Jurusan, Sistem Pendukung Keputusan
\end{abstract}

Abstract - Majors in high school and above have the aim, among others, to group students according to their skills, abilities, talents, and interests that are relatively similar. Besides determining the majors help prepare students to continue their st udies to Higher Education and choose the world of work. Based on research by the Indonesia Career Center Network (ICCN) in 2017, it is known that as many as $\mathbf{8 7 \%}$ of Indonesian students admit that the courses taken are not in line with their interests. In addition, as much as $\mathbf{7 1 . 7 \%}$ have a profession that is not in accordance with their education. Research conducted shows that there are $40 \%$ discrepancies in student majors. Based on the discrepancy of student competencies towards the majors they take, students as decision makers must really consider the criteria of ability and desire. The criteria set out in this case study are UN scores in Indonesian, English, Mathematics, Physics, Chemistry and Biology. National Examination (UN) scores for students will then be calculated using Fuzzy and Simple Additive Weighting (SAW) methods to obtain departmental recommendations that prospective students can take. The results of the research that has been done is in the form of making knowledge in decision support applications to recommend majors to students who will continue to tertiary level. The combination of Fuzzy and SAW methods can be used in recommending majors. It is expected that this application can help students in taking the right majors according to their interests and fields.

Keywords - Fuzzy, SAW, Department, Decision Support System

\section{Pendahuluan}

Penjurusan pada sekolah menengah ke atas memiliki tujuan antara lain mengelompokkan siswa sesuai kecakapan, kemampuan, bakat, dan minat yang relatif sama [2]. Selain itu penentuan jurusan membantu mempersiapkan siswa melanjutkan studi ke Perguruan Tinggi dan memilih dunia kerja. Membantu memperkokoh keberhasilan dan kecocokan atas prestasi yang akan dicapai di waktu mendatang. Setelah tamat dari SMA, siswa yang melanjutkan ke jenjang perguruan tinggi dapat memilih jurusan sesuai dengan keinginannya. Umumnya tes masuk perguruan tinggi harus megikuti tahapan tes kemampuan. Pengujian ini dilakukan untuk mendapatkan calon mahasiswa yang sesuai dengan kemampuan dan keinginannya dalam 
memilih jurusan. Penilaian ini dilakukan dengan beberapa indikator yang telah ditetapkan oleh Perguruan Tinggi.

Berdasar penelitian [3], diketahui sebanyak 87\% mahasiswa Indonesia mengakui bahwa jurusan yang diambil tidak sesuai dengan minatnya. Selain itu sebanyak $71,7 \%$ memiliki profesi yang tidak sesuai dengan pendidikannya. Penelitian yang dilakukan [2] yang berkaitan dengan ketidaksesuaian pemilihan jurusan siswa sebanyak $40 \%$.

Tabel 1. Persentase Ketidaksesuian Kompetensi [2]

\begin{tabular}{|c|l|}
\hline $\begin{array}{c}\text { Presentase } \\
\text { Siswa }\end{array}$ & \multicolumn{1}{|c|}{ Kesesuaian Kompetensi } \\
\hline $37 \%$ siswa & Sesuai dengan kompetensinya \\
\hline $23 \%$ siswa & $\begin{array}{l}\text { Ragu - ragu dengaan } \\
\text { kompetensinya }\end{array}$ \\
\hline $40 \%$ siswa & $\begin{array}{l}\text { Tidak sesuai dengan } \\
\text { kompetensinya }\end{array}$ \\
\hline
\end{tabular}

Berdasarkan ketidaksesuaian kompetensi siswa terhadap jurusan yang ditempuhnya maka siswa selaku pembuat keputusan harus benar - benar mempertimbangkan kriteria kemampuan dan keinginan. Kriteria yang ditetapkan dalam studi kasus ini adalah nilai UN Bahasa Indonesia, Bahasa Inggris, Matematika, Fisika, Kimia dan Biologi. Nilai Ujian Nasional (UN) siswa, selanjutnya akan dihitung menggunakan metode Fuzzy dan Simple Additive Weighting (SAW) untuk mendapatkan rekomendasi jurusan yang dapat diambil calon mahasiswa.

Metode SAW sering juga dikenal istilah metode penjumlahan terbobot. Konsep dasar metode SAW adalah mencari penjumlahan terbobot dari rating kinerja pada setiap alternatif pada semua atribut. Metode SAW membutuhkan proses normalisasi matriks keputusan (X) ke suatu skala yang dapat diperbandingkan dengan semua rating alternatif yang ada [4].

Logika fuzzy dapat digunakan untuk merepresentasikan masalah ketidakpastian. Sebuah bilangan fuzzy biasa memiliki himpunan fuzzy yang ditandai dengan pemberian interval dari 0 sampai 1. Logika fuzzy menggunakan fungsi keanggotaan dengan menggunakan kurva yang menunjukkan pemetaan titik-titik input data ke dalam nilai keanggotaannya yang memiliki interval antara 0 sampai 1 [6].

Kombinasi metode Fuzzy dan SAW telah banyak digunakan dalam penelitian. Penelitian Handayani [2] menggunakan kombinasi FSAW untuk menentukan jurusan pada tingkat Sekolah Menengah Atas (SMA) dan mampu membantu siswa dalam merekomendasikan jurusan pada tingkat SMA. Penerapan kombinasi Fuzzy - SAW digunakan pada seleksi siswa berprestasi. Itu hasil seleksi diperoleh dalam bentuk peringkat nilai peserta. Meski menggunakan yang sederhana perhitungan bobot, metode SAW FMADM bisa memberikan keputusan terbaik dalam proses pengambilan keputusan [5]. Penerapan Simple Additive Weighting (SAW) dapat diterapkan dalam menemukan alternatif terbaik untuk keputusan untuk membeli laptop. Penerapan metode toko komputer sangat membantu untuk menyediakan informasi kepada konsumen. Mereka dapat memilih laptop sesuai dengan selera dan kemampuan mereka. Dengan ini pendekatan, pengguna dapat menghitung keinginan pembelian barang [7]. Berdasarkan beberapa penelitian, maka penerapan kombinasi Fuzzy-SAW mampu membantu dalam pengambilan keputusan, untuk itu penelitian ini menggunakan metode FuzzySAW untuk membantu calon mahasiswa dalam menentukan jurusan di perguruan tinggi berdasarkan nilai Ujian Nasional (UN) dari mata pelajaran Bahasa Indonesia, Bahasa Inggris, Matematika, Fisika, Kimia, Biologi.

\section{Metodologi Penelitian}

\section{A. Sistem Pendukung Keputusan}

Sistem pendukung keputusan merupakan sistem berbasis komputer yang dapat membantu penggunanya dalam mengambil suatu keputusan untuk mengatasi permasalahan secara interaktif.

\section{B. Simple Additive Weighting (SAW)}

Metode Simple Additive Weighting (SAW) sering juga dikenal istilah metode penjumlahan terbobot. 
Konsep dasar metode SAW adalah mencari penjumlahan terbobot dari rating kinerja pada setiap alternatif pada semua kriteria [1] [9]. Metode SAW membutuhkan proses normalisasi matriks keputusan (X) ke suatu skala yang dapat diperbandingkan dengan semua rating alternatif yang ada. Metode ini merupakan metode yang paling terkenal dan paling banyak digunakan dalam menghadapi situasi Multiple Attribute Decision Making (MADM).

\section{Logika Fuzzy}

Logika fuzzy adalah suatu cara yang tepat untuk memetakan suatu ruang input ke dalam suatu ruang output [4]. Teori himpunan fuzzy dapat digunakan untuk merepresentasikan masalah ketidakpastian. Bilangan fuzzy biasa memiliki himpunan fuzzy yang ditandai dengan pemberian interval dari 0 sampai 1 [5]. Logika fuzzy menggunakan fungsi keanggotaan menggunakan kurva yang menunjukkan pemetaan titik-titik input data ke dalam nilai keanggotaannya menggunakan interval antara 0-1.

\section{Analisis Permasalahan}

Hasil analisa yang telah dilakukan, maka didapatkan permasalahan pada saat siswa akan melanjutkan ke jenjang perguruan tinggi dalam memilih jurusan. Penelitian [2] terdapat ketidaksesuaian kompetensi siswa terhadap jurusan sebanyak $40 \%$. Berdasarkan permasalahan ini, maka perlu sebuah penelitian dengan mengembangkan system pendukung keputusan yang dapat membantu merekomendasikan jurusan kepada calon mahasiswa baru dalam menentukan jurusan di perguruan tinggi berdasarkan nilai UN yang mereka dapatkan.

\section{E. Analisa Parameter}

Parameter merupakan indicator yang akan menjadi tolak ukur yang digunakan dalam perhitungan system pendukung keputusan. Parameter yang digunakan dalam memilih jurusan pada penelitian ini yaitu :
a. Nilai UN Bahasa Indonesia
b. Nilai UN Bahasa Inggris
c. Nilai UN Matematika
d. Nilai UN Fisika
e. Nilai UN Kimia
f. Nilai UN Biologi

III. HASIL DAN PEMBAHASAN

A. Perancangan (Desain)

1. Data Nilai Ujian Nasional

Tabel 2. Data Rata-rata Nilai UN

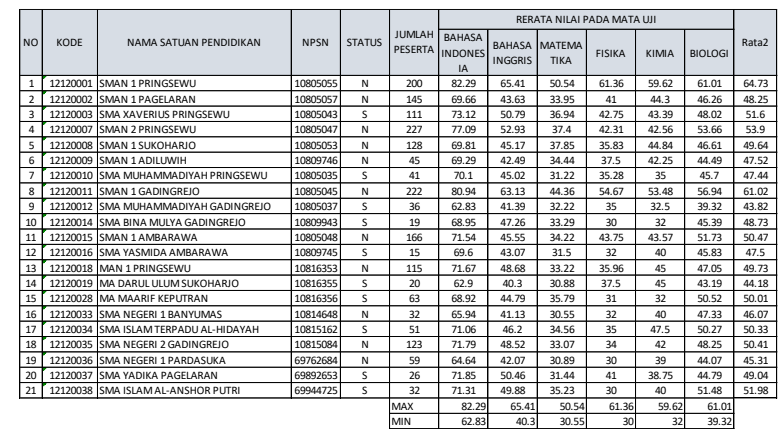

Tabel 3. Data Hasil UN Siswa

\begin{tabular}{|c|l|c|c|c|c|c|c|c|}
\hline NIS & \multicolumn{1}{|c|}{ Nama } & Jurusan & Bahasa & Inggris & MTK & Fisika & Kimia & Biologi \\
\hline 2012928375 & Heru Purwanto & IPA & 70 & 42 & 48 & 56 & 58 & 55 \\
\hline 2012203994 & Ahmad Sodiq & IPA & 62 & 45 & 40 & 47 & 43 & 57 \\
\hline 2012349589 & Yoyok Maryono & IPS & 74 & 57 & 46 & 37 & 36 & 40 \\
\hline 2011938478 & Rusliyanto & IPS & 65 & 40 & 43 & 45 & 42 & 50 \\
\hline 2010567853 & Budi Kurniawan & IPA & 60 & 50 & 45 & 38 & 60 & 53 \\
\hline 2010998812 & Ana Maulisa & IPA & 40 & 30 & 35 & 45 & 42 & 44 \\
\hline
\end{tabular}

Berdasarkan data nilai rata-rata Ujian Nasional dikabupaten Pringsewu dan wawancara kepada pakar yaitu para guru yang memiliki pengalaman dan pengetahuan pemilihan jurusan, maka didapatkan tabel pengetahuan untuk menentukan jurusan yang tepat berdasarkan nilai ujian nasional.

Tabel 4. Kecocokan Jurusan Berdasarkan Nilai UN

\begin{tabular}{|l|c|c|c|c|c|c|}
\hline \multirow{2}{*}{ Alternatif } & \multicolumn{7}{|c|}{ NilaI Ujian Nasional } \\
\cline { 2 - 7 } & B. Indo & B. Inggris & MTK & Fisika & Kimia & Biologi \\
\hline Komputer & $\geq 68$ & $\geq 55$ & $\geq 40$ & $\geq 34$ & $\geq 36$ & $\geq 50$ \\
\hline Kedokteran & $\geq 68$ & $\geq 62$ & $\geq 35$ & $\geq 58$ & $\geq 57$ & $\geq 60$ \\
\hline Sipil & $\geq 68$ & $\geq 45$ & $\geq 45$ & $\geq 55$ & $\geq 38$ & $\geq 45$ \\
\hline Hukum & $\geq 80$ & $\geq 64$ & $\geq 35$ & $\geq 34$ & $\geq 36$ & $\geq 45$ \\
\hline Ekonomi & $\geq 75$ & $\geq 45$ & $\geq 48$ & $\geq 34$ & $\geq 36$ & $\geq 45$ \\
\hline
\end{tabular}

Berdasarkan tabel kecocokan diatas, selanjutnya dibuat kurva dan fungsi keanggotaan berdasarkan parameter nilai ujian nasional.

\section{Penilaian Parameter}

Penilaian untuk masing masing parameter menggunakan kurva linier dan fungsi keanggotaan pada Logika Fuzzy seperti pada tabel 5. Berikut.

Tabel 5. Parameter UN Terhadap Jurusan Komputer 


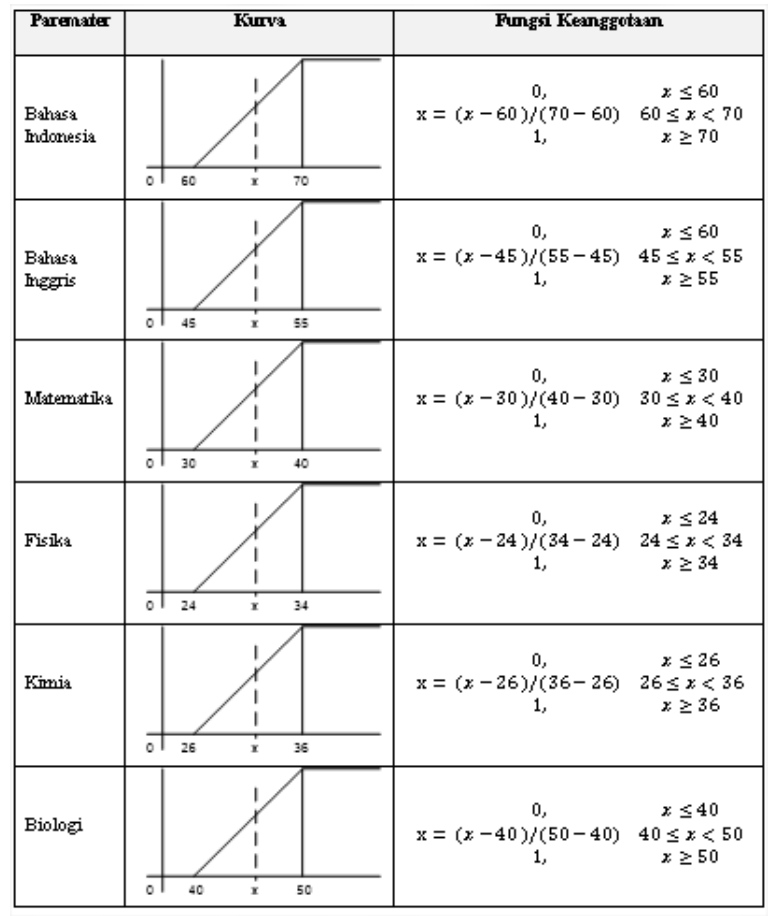

Nilai yang digunakan dalam perhitungan adalah nilai keanggotaan yang telah dihitung menggunakan fungsi keanggotaan. Nilai-nilai tersebut dikonversikan ke dalam kriteria dan diubah ke bilangan fuzzy. Sebagai contoh terdapat alumni bernama BUDI memiliki nilai UN Bahasa Indonesia 60, Bahasa Inggris 45, MTK 40, Fisika 47, Kimia 43 dan Biologi 47, maka nilai tersebut dikonversi dengan perhitungan menggunakan fungsi keanggotaan dengan hasil pada tabel 6 .

Tabel 6. Nilai Keanggotaan

\begin{tabular}{|c|c|c|c|c|c|c|}
\hline \multirow[b]{2}{*}{ Alteruatif } & \multicolumn{6}{|c|}{ Kriterin } \\
\hline & $\begin{array}{c}\text { B. Indo } \\
\text { (C) }\end{array}$ & \begin{tabular}{|c|} 
B. Inggris \\
(C)2) \\
\end{tabular} & $\begin{array}{l}\text { MTK } \\
\left(C_{3}\right)\end{array}$ & $\begin{array}{l}\text { Fisilka } \\
\text { (C4) }\end{array}$ & $\begin{array}{l}\text { Kimin } \\
\text { (CS) }\end{array}$ & $\begin{array}{l}\text { Biologi } \\
\left(\mathrm{CO}_{0}\right)\end{array}$ \\
\hline Korpoter & 0.2 & 0 & 1 & 1 & 1 & 1 \\
\hline Kedokteran & 0.4 & 0 & 1 & 0 & 0 & 0.7 \\
\hline Sipil & 0.4 & 1 & 0.5 & 02 & 1 & 1 \\
\hline Hum & 0 & 0 & 1 & 1 & 1 & 1 \\
\hline Eronomi & 0 & 1 & 0.2 & 1 & 1 & 1 \\
\hline $\mathrm{Max}$ & 0.4 & 1 & 1 & 1 & 1 & 1 \\
\hline
\end{tabular}

3. Normaliasi Metode SAW

Normalisasi dilakukan berdasarkan rumus berikut :<smiles>[Y][R]([H])(C)CC(=[V])CC</smiles>

Keterangan :

- Jika j adalah atribut keuntungan (benefit)

- Jika j adalah atribut biaya (cost)

Normalisasinya adalah sebagai berikut :

Normalisasi untuk jurusan Komputer sebagai berikut :

$$
\begin{aligned}
& r 11=\frac{0.2}{\max (0.2 ; 0.4 ; 0.4 ; 0 ; 0)}=\frac{0.2}{0.4}=0.5 \\
& r 12=\frac{0}{\max (0 ; 0 ; 1 ; 0 ; 1)}=\frac{0}{1}=0
\end{aligned}
$$

$r 13=\frac{1}{\max (1 ; 1 ; 0.5 ; 1 ; 0.2)}=\frac{1}{1}=1$

$r 14=\frac{1}{\max (1 ; 0 ; 0.2 ; 1 ; 1)}=\frac{1}{1}=1$

$r 15=\frac{1}{\max (1 ; 0 ; 1 ; 1 ; 1)}=\frac{1}{1}=1$

$r 16=\frac{1}{\max (1 ; 0.7 ; 1 ; 1 ; 1)}=\frac{1}{1}=1$

Normalisasi untuk jurusan Kedokteran sebagai berikut :

$$
\begin{aligned}
& r 21=\frac{0.4}{\max (0.2 ; 0.4 ; 0.4 ; 0 ; 0)}=\frac{0.4}{0.4}=1 \\
& r 22=\frac{0}{\max (0 ; 0 ; 1 ; 0 ; 1)}=\frac{0}{1}=0 \\
& r 23=\frac{1}{\max (1 ; 1 ; 0.5 ; 1 ; 0.2)}=\frac{1}{1}=1
\end{aligned}
$$


$r 24=\frac{0}{\max (1 ; 0 ; 0.2 ; 1 ; 1)}=\frac{0}{1}=1$

$r 25=\frac{0}{\max (1 ; 0 ; 1 ; 1 ; 1)}=\frac{0}{1}=1$

$r 26=\frac{0.7}{\max (1 ; 0.7 ; 1 ; 1 ; 1)}=\frac{0.7}{1}=0.7$

Normalisasi untuk jurusan Teknik Sipil sebagai berikut :

$$
\begin{aligned}
& r 31=\frac{0.4}{\max (0.2 ; 0.4 ; 0.4 ; 0 ; 0)}=\frac{0.4}{0.4}=1 \\
& r 32=\frac{1}{\max (0 ; 0 ; 1 ; 0 ; 1)}=\frac{1}{1}=1 \\
& r 33=\frac{0.5}{\max (1 ; 1 ; 0.5 ; 1 ; 0.2)}=\frac{0.5}{1}=0.5 \\
& r 34=\frac{0.2}{\max (1 ; 0 ; 0.2 ; 1 ; 1)}=\frac{0.2}{1}=0.2 \\
& r 35=\frac{1}{\max (1 ; 0 ; 1 ; 1 ; 1)}=\frac{1}{1}=1 \\
& r 36=\frac{1}{\max (1 ; 0.7 ; 1 ; 1 ; 1)}=\frac{1}{1}=1
\end{aligned}
$$

Normalisasi untuk jurusan Hukum sebagai berikut

$$
\begin{aligned}
& r 21=\frac{0}{\max (0.2 ; 0.4 ; 0.4 ; 0 ; 0)}=\frac{0}{0.4}=0 \\
& r 22=\frac{0}{\max (0 ; 0 ; 1 ; 0 ; 1)}=\frac{0}{1}=0 \\
& r 23=\frac{1}{\max (1 ; 1 ; 0.5 ; 1 ; 0.2)}=\frac{1}{1}=1 \\
& r 24=\frac{1}{\max (1 ; 0 ; 0.2 ; 1 ; 1)}=\frac{1}{1}=1 \\
& r 25=\frac{1}{\max (1 ; 0 ; 1 ; 1 ; 1)}=\frac{1}{1}=1
\end{aligned}
$$

$r 26=\frac{1}{\max (1 ; 0.7 ; 1 ; 1 ; 1)}=\frac{1}{1}=1$

Normalisasi untuk jurusan Ekonomi sebagai berikut :

$$
r 21=\frac{0}{\max (0.2 ; 0.4 ; 0.4 ; 0 ; 0)}=\frac{0}{0.4}=0
$$

$r 22=\frac{1}{\max (0 ; 0 ; 1 ; 0 ; 1)}=\frac{1}{1}=1$

$r 23=\frac{0.2}{\max (1 ; 1 ; 0.5 ; 1 ; 0.2)}=\frac{0.2}{1}=0.2$

$r 24=\frac{1}{\max (1 ; 0 ; 0.2 ; 1 ; 1)}=\frac{1}{1}=1$

$r 25=\frac{1}{\max (1 ; 0 ; 1 ; 1 ; 1)}=\frac{1}{1}=1$

$r 26=\frac{1}{\max (1 ; 0.7 ; 1 ; 1 ; 1)}=\frac{1}{1}=1$

Didapatkan hasil normalisasi sebagai berikut:

$$
R=\left(\begin{array}{cccccc}
0.5 & 0 & 1 & 0 & 1 & 1 \\
1 & 0 & 1 & 0 & 0 & 0.7 \\
1 & 1 & 0.5 & 0.2 & 1 & 1 \\
0 & 0 & 1 & 1 & 1 & 1 \\
0 & 1 & 0.2 & 1 & 1 & 1
\end{array}\right)
$$

Proses perangkingan dilakukan dengan menggunakan vektor bobot masing-masing kriteria yang telah ditetapkan oleh pengambil keputusan. Vektor bobotnya adalah sebagai berikut :
$\mathrm{W} 1=\left[\begin{array}{llllll}0.15 & 0.25 & 0.3 & 0.1 & 0.1 & 0.1\end{array}\right]$
$\mathrm{W} 2=\left[\begin{array}{llllll}0.1 & 0.1 & 0.1 & 0.2 & 0.25 & 0.25\end{array}\right]$
$\mathrm{W} 3=\left[\begin{array}{llllll}0.1 & 0.1 & 0.2 & 0.25 & 0.25 & 0.1\end{array}\right]$
$\mathrm{W} 4=\left[\begin{array}{llllll}0.3 & 0.25 & 0.15 & 0.1 & 0.1 & 0.1\end{array}\right]$
$\mathrm{W} 5=\left[\begin{array}{llllll}0.2 & 0.2 & 0.3 & 0.1 & 0.1 & 0.1\end{array}\right]$

Hasil perkalian antara matriks $\mathrm{W} * \mathrm{R}$ adalah sebagai berikut : 
$\mathrm{W} * \mathrm{R}$

$=\left(\begin{array}{cccccc}0.076 & 0 & 0.3 & 0 & 0.1 & 0.1 \\ 0.1 & 0 & 0.1 & 0 & 0 & 0.175 \\ 0.1 & 0.1 & 0.1 & 0.05 & 0.25 & 0.1 \\ 0 & 0 & 1 & 0.1 & 0.1 & 0.1 \\ 0 & 0.2 & 0.06 & 0.1 & 0.1 & 0.1\end{array}\right)$

Langkah selanjutnya adalah penjumlahan masingmasing kriteria untuk mendapatkan hasil perangkingan kriterianya. Baris pertama dari matriks $\mathrm{W} * \mathrm{R}$ :

$\mathrm{A} 1=0.576+0+0.3+0+0.1+0.1=0.575$

$\mathrm{A} 2=0.1+0+0.1+0+0+0.175=0.375$

$\mathrm{A} 3=0.7+0.1+0.1+0.1+0.05+0.25+0.1=0.7$

$\mathrm{A} 4=0+0+1+0.1+0.1+0.1=0.45$

$\mathrm{A} 5=0+0.2+0.06+0.1+0.1+0.1=0.56$

Perangkingan diurutkan dari hasil penjumlahan kriteria paling besar ke paling kecil. Nilai penjumlahan alternatif terbesar ada pada A3, sehingga alternatif A3 (Teknik Sipil) adalah alternatif yang terpilih sebagai alternatif terbaik.

\section{B. Impelementasi Sistem}

Halaman ini digunakan untuk menghitung menggunakan logika fuzzy dan metode SAW untuk memberikan rekomendasi jurusan. Hasil dari perhitungan berupa nilai perangkingan yang diurutkan dari hasil penjumlahan kriteria paling besar ke paling kecil. Nilai penjumlahan alternatif terbesar ada pada A3, sehingga alternatif A3 (Teknik Sipil) adalah alternatif yang terpilih sebagai alternatif terbaik.

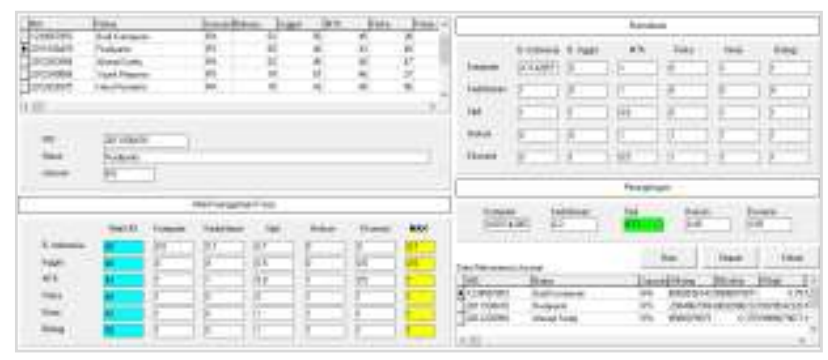

Gambar 1. Halaman Perhitungan Rekomendasi Jurusan
Berdasarkan perhitungan dengan nama Ahmad Sodiq dan nilai ujian nasional bahasa Indonesia 62, Bahasa Inggris 45, MTK 40, Fisika 47, Kimia 43 dan Biologi 57, setelah dihitung menggunakan logika fuzzy dan metode SAW, maka didapat nilai rekomendasi terbesar yaitu Jurusan Teknik Sipil, namun seluruh nilai jurusan ditampilkan sehingga pengambil keputusan dapat menentukan sesuai keinginannya.

\section{Hasil Penelitian}

Hasil dari penelitian yang telah dilakukan adalah berupa pembuatan pengetahuan dalam aplikasi pendukung keputusan untuk merekomendasikan jurusan kepada siswa yang akan melanjutkan ke jenjang perguruan tinggi. Kombinasi metode Fuzzy dan SAW dapat digunakan dalam merekomendasikan untuk penentuan jurusan. Diharapkan dengan adanya aplikasi ini dapat membantu para siswa dalam mengambil jurusan yang tepat.

\section{KESIMPULAN}

Berdasarkan dari hasil pembahasan yang telah dilakukan, terdapat beberapa kesimpulan yaitu sebagai berikut:

1. Perancangan sistem dalam membangun sistem pendukung keputusan untuk merekomendasikan jurusan menggunakan metode pengembangan waterfall. Pada tahap pengkodean menggunakan bahasa pasca dengan GUI Borland Delphi dan basisdata My SQL.

2. Penerapan metode fuzzy digunakan untuk menentukan nilai keanggotaan dari setia kritera lalu dihitung normalisasi dan perangkingan menggunakan metode Simple Additive Weighted (SAW)

3. Penentuan kriteria diambil dari nilai Ujian Nasional siswa yang telah diolah dan pengetahuan pakar dalam hal pendidikan. 


\section{REFERENSI}

[1] Fishburn, P.C.1967." Additive Utilities with Incomplete Product Set: Application to Priorities and Assignments"., Blackwell Publishing. New Jersey

[2] Dian Novita Handayani, Fitro Nur Hakim, Achmad Solechan, "SISTEM Pendukung Keputusan Untuk Pemilihan Jurusan Menggunakan

[3] Indonesia Career Center Network $\quad$ (ICCN) tahun 2017 http://www.careercenter.id/

[4] Kusumadewi, Sri dan Purnomo Hari. 2010, “Aplikasi Logika Fuzzy”, Cetakan Pertama, Graham Ilmu, Yogyakarta

[5] Widayanti Deni, Oka-Sudana and Arya Sasmita, 2013., Analysis and Implementation Fuzzy Multi Attribute Decision Making SAW Method for Selection of High Achieving Students inFaculty Level.

[6] Zadeh, L. A. (1994). The concept of a linguistic variable and its application to approximate reasoning-III. Information sciences, $\quad 9(1), 43-80$

[7] Khairul, Manogari Simaremare, Andysah Putera Utama Siahaan. 2016. "Decision Support System in Selecting The Appropriate Laptop Using Simple Additive Weighting”. $\quad$ IJRTER2016, All Rights Reserved

[8] Turban, Efraim dan Jay E Aronson. 2005. Decission Support Systems and Intelligent Systems. Yogyakarta: Andi Offset

[9] Mac Crimmon, K.R.1968. "Decision Making among Multiple Atribut Alternatives: a Survey and Consolidated Approach" 